\title{
Review \\ Bench-to-bedside review: Candida infections in the intensive care unit
}

\author{
Marie Méan, Oscar Marchetti and Thierry Calandra
}

Infectious Diseases Service, Department of Medicine, Centre Hospitalier Universitaire Vaudois and University of Lausanne, Rue du Bugnon 46, $\mathrm{CH}-1011$ Lausanne, Switzerland

Corresponding author: Thierry Calandra, Thierry.Calandra@chuv.ch

Published: 22 January 2008

This article is online at http://ccforum.com/content/12/1/204

Critical Care 2008, 12:204 (doi:10.1186/cc6212)

(c) 2008 BioMed Central Ltd

\begin{abstract}
Invasive mycoses are life-threatening opportunistic infections and have emerged as a major cause of morbidity and mortality in critically ill patients. This review focuses on recent advances in our understanding of the epidemiology, diagnosis and management of invasive candidiasis, which is the predominant fungal infection in the intensive care unit setting. Candida spp. are the fourth most common cause of bloodstream infections in the USA, but they are a much less common cause of bloodstream infections in Europe. About one-third of episodes of candidaemia occur in the intensive care unit. Until recently, Candida albicans was by far the predominant species, causing up to two-thirds of all cases of invasive candidiasis. However, a shift toward non-albicans Candida spp., such as C. glabrata and C. krusei, with reduced susceptibility to commonly used antifungal agents, was recently observed. Unfortunately, risk factors and clinical manifestations of candidiasis are not specific, and conventional culture methods such as blood culture systems lack sensitivity. Recent studies have shown that detection of circulating $\beta$-glucan, mannan and antimannan antibodies may contribute to diagnosis of invasive candidiasis. Early initiation of appropriate antifungal therapy is essential for reducing the morbidity and mortality of invasive fungal infections. For decades, amphotericin B deoxycholate has been the standard therapy, but it is often poorly tolerated and associated with infusion-related acute reactions and nephrotoxicity. Azoles such as fluconazole and itraconazole provided the first treatment alternatives to amphotericin B for candidiasis. In recent years, several new antifungal agents have become available, offering additional therapeutic options for the management of Candida infections. These include lipid formulations of amphotericin B, new azoles (voriconazole and posaconazole) and echinocandins (caspofungin, micafungin and anidulafungin).
\end{abstract}

\section{Introduction}

Fungi have emerged worldwide as an increasingly frequent cause of opportunistic infections. A survey of the epidemiology of sepsis conducted in the USA [1] revealed that the incidence of fungal sepsis increased threefold between 1979 and 2000. In contrast, numerous studies have revealed either no increase or sometimes even a decrease in the incidence of Candida sepsis [2-4]. Candida and Aspergillus spp. are the most frequent causes of invasive fungal infections and are associated with high morbidity and mortality $[3,5,6]$. The incidence of invasive candidiasis is sevenfold to 15-fold higher than that of invasive aspergillosis [3]. Originally described in immunocompromised hosts, primarily cancer patients, opportunistic fungal pathogens have now been recognized as a frequent cause of infection in surgical and critically ill patients.

The epidemiology of invasive mold infections is changing. Invasive aspergillosis is now also occurring in intensive care unit (ICU) patients, including mechanically ventilated patients and patients with chronic lung diseases treated with corticosteroids [7]. Moreover, the number of strains of nonfumigatus Aspergillus spp. is on the rise and multi-resistant non-Aspergillus mould infections are emerging. Although these are undoubtedly important epidemiological changes, this review article focuses on recent advances in our understanding of the epidemiology, diagnosis and treatment of invasive candidiasis, which is the predominant fungal infection occurring in critically ill patients.

\section{Epidemiology}

Candida is now the fourth leading micro-organism responsible for bloodstream infections in the USA, outnumbering all Gram-negative bacilli [8-10]. Data from 790 ICUs reporting to the US National Nosocomial Infection Surveillance system between 1990 and 1999 [8,11] showed that Candida spp. were responsible for $5 \%$ to $10 \%$ of all bloodstream infections.

Studies of Candida infections in Europe have revealed significant differences from recent trends observed in the USA. In Europe, Candida is usually the sixth to the 10th cause of 
nosocomial bloodstream infections [4,12-14]. In a survey conducted by the Fungal Infection Network of Switzerland between 1991 and 2000 [4], ICUs and surgical wards accounted for about two-thirds of all episodes of candidaemia. The incidence of candidaemia (on average 0.5 episodes/10,000 patient-days per year) was stable over this 10-year period and was five to 10 times higher in ICUs than in other wards.

During recent decades, several countries around the world have witnessed a change in the epidemiology of Candida infections, characterized by a progressive shift from a predominance of Candida albicans toward a predominance of non-albicans Candida spp. (including C. glabrata and C. krusei) [15]. C. glabrata has progressively increased and now accounts for $15 \%$ to $20 \%$ of infections in most countries $[16,17]$. There is growing evidence suggesting a role in this epidemiological shift for increasing use of azole agents. Reduced susceptibility to commonly used antifungal agents has also been observed in some North American and European centres [18].

In ICU patients, the most common types of Candida infections are bloodstream infections, catheter-related infections, intra-abdominal infections and urinary tract infections [19-23]. Invasive candidiasis is recognized as a leading cause of morbidity and mortality in both immunocompetent and immunocompromised critically ill patients, with reported crude and attributable mortality rates of more than $40 \%$ to $60 \%$ and $20 \%$ to $40 \%$, respectively [13,23-29]. Of note, however, is that in the most recent clinical trials of new antifungal agents [30-35] the overall short-term (end of therapy) and long-term mortality (end of follow up) associated with candidaemia were found to be in the range of $15 \%$ to $20 \%$ and $30 \%$ to $40 \%$, respectively (Figure 1). Candidaemia is also associated with prolonged duration of mechanical ventilation and hospital stay, and increased health care costs [28,36-38].

\section{Risk factors}

Two main factors predispose to infections with Candida spp.: colonization of skin and mucous membranes with Candida and alteration of natural host barriers (wounds, surgery, and insertion of indwelling intravascular and urinary catheters). The gastrointestinal tract, the skin and the urogenital tract are the main portals of entry for Candida infections. Colonization by Candida spp. has clearly been established as a major risk factor for invasive candidiasis [39]. Together with colonization with Candida induced by profound alteration of the endogenous flora resulting from prolonged broad-spectrum antibiotic therapy and loss of integrity of skin and mucosal barriers, surgery (especially of the abdominal compartment), total parenteral nutrition, acute renal failure, haemodialysis and treatment with immunosuppressive agents are major risk factors for invasive infections with Candida spp. [23,25,40]. Debilitating underlying diseases, critically ill status (as reflec- ted by high Acute Physiology and Chronic Health Evaluation [APACHE] II score), antacids and mechanical ventilation have also frequently been associated with invasive candidiasis. Length of stay in the ICU is also associated with increased risk for Candida infections, which rises rapidly after 7 to 10 days $[23,29,41,43]$.

Prediction rules and scores for identification of non-neutropenic critically ill patients at risk for invasive candidiasis have been reported [39,44-48]. Growth of Candida in semiquantitative cultures (plating of specimens using the clockstreak technique and a calibrated loop) from multiple body sites has been used to predict the risk for invasive candidiasis [39]. The colonization index, calculated by dividing the number of colonized sites by the number of cultured sites, was found to be significantly higher in patients who developed invasive candidiasis than in control individuals $(0.70 \pm 0.17$ versus $0.47 \pm 0.17 ; P<0.01)$ [39]. More recently, based on a prospective, cohort, observational, multicentre study that included 73 medical-surgical ICUs in Spain [48], a 'Candida score' was developed with the aim being to initiate antifungal therapy early. An adjusted logit model indicated that surgery on ICU admission, total parenteral nutrition, colonization at multiple sites with Candida and severe sepsis were associated with an increased risk for proven Candida infection. Patients with a Candida score, calculated using these variables, of 2.5 or more were 7.5 times more likely to have Candida infections than patients with a score of less than 2.5 .

Most recently, an analysis of risk factors in 2,890 patients who stayed in the ICU for more than 4 days led to the development and validation of a clinical prediction rule for the early diagnosis of invasive candidiasis in the ICU [47]. The best prediction rule used a combination of the following factors: any systemic antibiotic or presence of central venous catheter and at least two other risk factors, including total parenteral nutrition, major surgery, pancreatitis, any use of steroids and use of immunosuppressive agents. This prediction rule exhibited a sensitivity of $34 \%$, a specificity of $90 \%$, a positive predictive value of $10 \%$ and a negative predictive value of $97 \%$. This clinical rule may therefore help clinicians to rule out invasive candididiasis. However, data on the use of these risk assessment scores for guiding patient management are not yet available and their clinical utility remains to be established in prospective clinical studies.

\section{Diagnosis}

Given that rapid initiation of appropriate antifungal therapy is crucial for reducing mortality $[13,49]$, prompt diagnosis of infection is of the utmost importance. Unfortunately, diagnosing invasive fungal infections remains difficult and is often delayed. Indeed, blood cultures lack sensitivity (reported to be <50\%) [50] and usually become positive late [51]. Invasive tissue sampling is often problematic in critically ill ICU patients. Radiological signs appear often late in the 

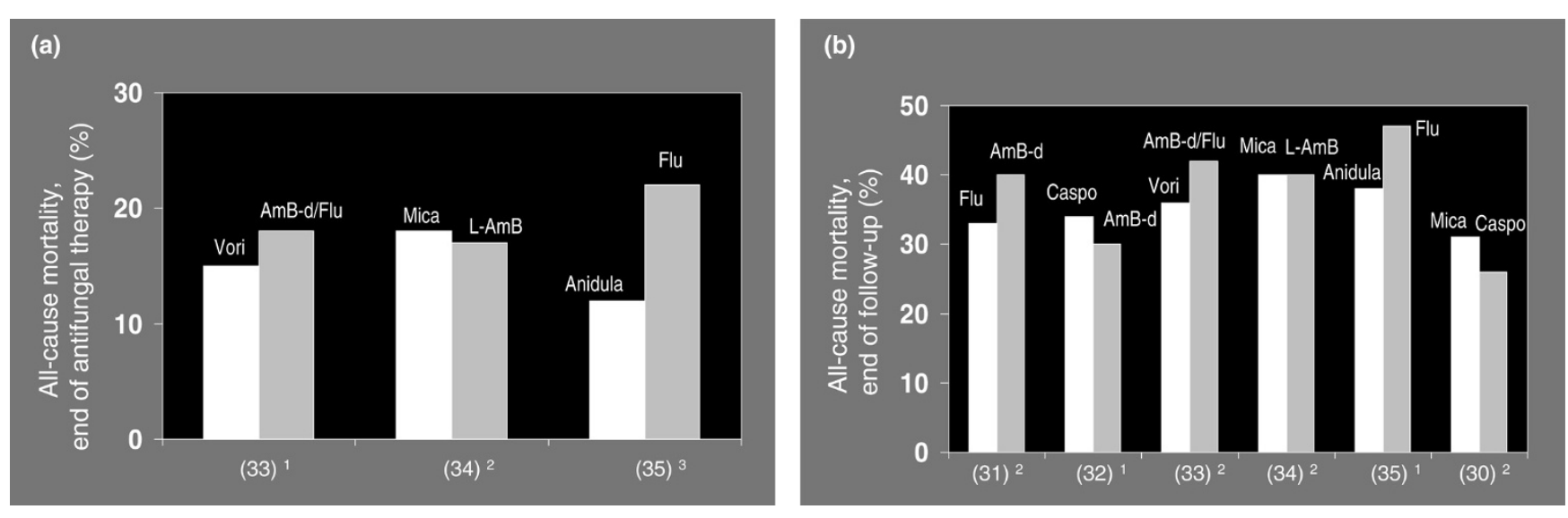

Mortality rates associated with Candida infections. Shown are rates of all-cause mortality from candidaemia or invasive candidiasis at (a) the end of antifungal therapy and (b) the end of follow up in recent randomized clinical trials. Numbers given in parenthesis on the $x$-axis indicate the reference numbers of the clinical trials. Duration of follow-up in panel a: ${ }^{1} 2$ weeks, 22 to 4 weeks and ${ }^{3} 2$ to 3 weeks. Duration of follow-up in panel b: ${ }^{1} 8$ to 10 weeks and 212 to 14 weeks. AmB-d, amphotericin B-deoxycholate; Anidula, anidulafungin; Caspo, caspofungin; Flu, fluconazole; L-AmB, amphotericin B, liposomal preparation; Mica, micafungin; Vori, voriconazole.

course of infection. Moreover, the European Organization for Research and Treatment of Cancer/Mycoses Study Group criteria for diagnosis of invasive mycoses [52], which are based on clinical, microbiological and radiological criteria, were developed in immunocompromised patients and may not apply to ICU patients. The need for sensitive and specific diagnostic tools has led investigators to look for non-culturebased methods aimed at detecting circulating fungal metabolites, antigens, antibodies and fungal DNA.

Serological tests consist of detection of components of the fungal cell wall, such as mannan, galactomannan and $\beta-(1,3)$ D-glucan, or antibodies directed against these antigens (antimannan) in blood or other body fluids. These tests have been shown to perform well in clinical studies. For example, three studies were conducted including $5 \%$ to $30 \%$ of critically ill patients [53-55]. Measurements of mannan and/or antimannan led to earlier diagnosis of Candida infection when compared with blood cultures [53,54]. Sensitivity and specificity (respectively) were $40 \%$ and $98 \%$ for mannan and $53 \%$ and $94 \%$ for anti-mannan antibodies, and $80 \%$ to $90 \%$ when combining the two tests [55]. Assays for detection of $\beta$ (1,3)-D-glucan are used widely in Japan, and one of these assays (Fungitell; ACC, Falmouth, MA, USA) was recently approved by the US Food and Drug Administration. Studies conducted with $\beta$-(1,3)-D-glucan assays have yielded sensitivities ranging from $69 \%$ to $97 \%$, specificities ranging from $87 \%$ to $100 \%$, and positive and negative predictive values ranging from $59 \%$ to $96 \%$ and $75 \%$ to $97 \%$, respectively [56-59]. Given these excellent negative predictive values $\beta$ $(1,3)$-D-glucan tests can help to rule out invasive candidiasis. Unfortunately, little information has been published thus far on use of $\beta-(1,3)$-D-glucan tests in the ICU setting.
Molecular diagnostic tests for detection of Candida DNA in either blood or tissues have been described [60,61]. Albeit promising, relatively few data have been published on the performance of the detection of fungal DNA in high-risk critically ill patients. In addition, these tests are not yet commercially available.

Noninvasive diagnostic tools look promising for early diagnosis of invasive candidiasis. Clinical studies should now be conducted to evaluate their utility for guiding therapeutic decisions (see Pre-emptive therapy, below).

\section{Antifungal therapy \\ Prophylaxis}

Few prophylactic studies have been performed in ICU patients [43,62-67]. Earlier studies conducted by Savino and coworkers [64] and Slotman and Burchard [63] compared the efficacy of prophylactic administration of oral clotrimazole, ketoconazole, or nystatin with that of placebo in patients selected based either on expected length of stay in the ICU or on baseline risk factors. The results of these underpowered studies revealed either no effect or only a modest impact of prophylaxis on occurrence of Candida infections [68].

In contrast, several more recent studies $[43,62,65]$ indicated that high-risk critically ill patients may benefit from antifungal prophylaxis. Fluconazole prophylaxis was found to prevent intra-abdominal candidiasis in high-risk surgical patients with recurrent gastrointestinal perforations or anastomotic leaks [65]. The risk for intra-abdominal candidiasis was reduced eightfold in patients receiving fluconazole $(400 \mathrm{mg} /$ day). One fluconazole-treated patient (4\%) developed Candida perito- 
nitis as compared with seven placebo-treated patients (35\%; $P=0.02$ ). The number of patients needed to prevent one episode of intra-abdominal candidiasis was 3 , indicating that prophylaxis had considerable impact. Four (20\%) patients died from fungal infections in the placebo group, but none did so in the fluconazole group $(P=0.04)$. In a randomized, double-blind, placebo-controlled trial conducted in medical and surgical ICU patients ventilated for at least 48 hours and expected to stay in the ICU for another 72 hours [62], fluconazole prophylaxis $(100 \mathrm{mg} /$ day) exerted a modest protective effect against Candida colonization. Although it did not prevent the development of severe Candida infections, which was the primary study end-point, fluconazole prophylaxis markedly reduced the number of episodes of candidaemia. In the third study, that conducted by Pelz and coworkers [43] in 260 surgical patients expected to stay in the ICU for more than 3 days, 11 (9\%) fungal infections occurred in the fluconazole group as compared with 20 $(16 \%)$ in the placebo group $(P<0.05)$. Mortality was similar between the two treatment groups.

Overall, these three classic studies strongly suggest that azole prophylaxis has the capacity to reduce the incidence of invasive candidiasis in surgical and ICU patients. However, an important issue remains how to identify those patients who are likely to benefit from prophylaxis without unnecessarily exposing patients who are at either low or no risk to antifungal agents. Indeed, according to a Cochrane review on antifungal agents for the prevention of fungal infections in non-neutropenic critically ill patients [69], the number of patients who should be treated with fluconazole to prevent one Candida infection is 94 . This estimate, based on an incidence of fungal infection of $2 \%$, ranged from 9 in high-risk patients to 188 in low-risk patients. Whether antifungal prophylaxis may have an impact on mortality remains a matter of debate. Although no individual study demonstrates an impact of azole prophylaxis on mortality, the recent Cochrane meta-analysis [69] indicated that prophylaxis did reduce the overall mortality in non-neutropenic critically ill patients. In the 2004 guidelines of the Infectious Diseases Society of America on treatment of candidiasis [19], routine use of antifungal prophylaxis in the general ICU setting was discouraged. However, it was suggested that fluconazole prophylaxis should be considered in carefully selected patients (a recommendation classified as $A 1$, based on the strength of the evidence). These guidelines are being revised and an updated version should be available in 2008 .

\section{Pre-emptive therapy}

There is an extreme paucity of studies on pre-emptive antifungal therapy. In a study conducted between 1998 and 2002 in a surgical ICU in France [70], administration of targeted pre-emptive intravenous fluconazole therapy (fluconazole: $800 \mathrm{mg}$ loading dose and then $400 \mathrm{mg} /$ day for 2 weeks) based on colonization indexes was shown to prevent development of proven candidiasis in ICU patients, when compared with an historical control group of patients. A study conducted in Japan examined the effects of early initiation of pre-emptive therapy with an azole (fluconazole or miconazole in $78 \%$ and $2 \%$ of patients, respectively) or an echinocandin (micafungin in 20\%), which was initiated based on a combination of Candida colonization at multiple sites and a positive $\beta$ - $(1,3)$-D-glucan test [71]. The findings indicated that early pre-emptive strategy prevented candidaemia but had no impact on mortality.

\section{Treatment of documented Candida infections}

Polyenes

For decades amphotericin B deoxycholate has been the standard therapy for invasive fungal infections. Unfortunately, amphotericin B deoxycholate is often poorly tolerated and associated with acute infusion-related reactions and nephrotoxicity. During the late 1970s and 1980s, the development of azoles (miconazole, ketoconazole, fluconazole and itraconazole) provided alternative therapeutic options to amphotericin B for the treatment of candidiasis. In recent years, several new antifungal agents have become available, further enlarging the antifungal armamentarium (Table 1) [30-35]. These include lipid formulations (colloidal dispersion, lipid complex and liposomal) of amphotericin B, new azoles (voriconazole and posaconazole) and echinocandins (caspofungin, micafungin and anidulafungin). Lipid formulations of amphotericin B (colloidal dispersion, lipid complex and liposomal) are better tolerated than amphotericin B deoxycholate and have been used mainly in patients who are intolerant to conventional amphotericin B or are unlikely to tolerate it because of altered renal function. Few studies have compared the efficacy of amphotericin B deoxycholate with that of lipid formulations for the treatment of patients with invasive candidiasis [72,73]. Small noncomparative studies $[72,73]$ suggested that lipid formulations of amphotericin B are as efficacious as conventional amphotericin B. High costs, a relative paucity of clinical data and existence of alternative antifungal therapies (azoles and echinocandins) explain why lipid formulations have generally been used as second-line therapy in patients with refractory invasive candidiasis.

\section{Triazoles}

In a multicentre study in non-neutropenic patients with candidaemia, fluconazole ( $400 \mathrm{mg} /$ day) was found to be as efficacious as and better tolerated than amphotericin $B$ deoxycholate (0.5 to $0.6 \mathrm{mg} / \mathrm{kg}$ per day) [31]. Fluconazole remains one of the most commonly used antifungal agents for the treatment of Candida infections. However, innate (C. krusei) or emerging (especially C. glabrata and C. guilliermondi) resistance to azoles among non-albicans Candida spp. has been noted in various regions of the world [16,17], which may limit the use of fluconazole as empirical therapy for yeast bloodstream infections in critically ill patients before species identification and results of antifungal susceptibility testing are known. Data on the efficacy of high doses (800 to 


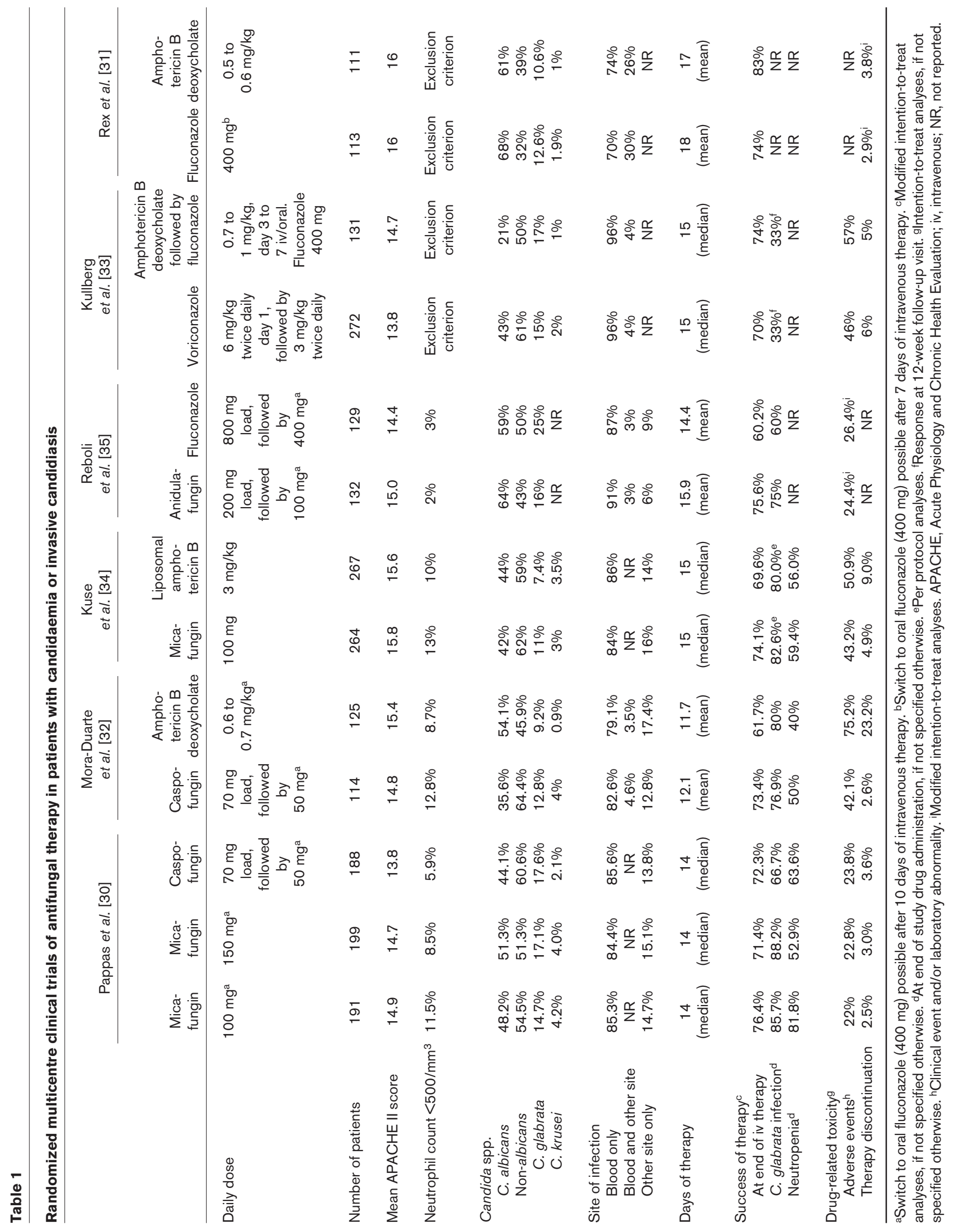


$1,200 \mathrm{mg}$ ) of fluconazole for treatment of less susceptible Candida strains are lacking.

Voriconazole, a second-generation triazole that is active against all Candida spp., is a new option for intravenous and oral therapy of Candida infections [74]. In a randomized, open-label, comparative multicentre, noninferiority trial conducted in patients with invasive Candida infections [33], voriconazole $(6 \mathrm{mg} / \mathrm{kg}$ per day after a $12 \mathrm{mg} / \mathrm{kg}$ loading dose on day 1) was shown to be at least as effective as and safer than amphotericin B deoxycholate ( 0.7 to $1 \mathrm{mg} / \mathrm{kg}$ per day) followed by intravenous or oral fluconazole ( $400 \mathrm{mg} / \mathrm{day})$. Transient, fully reversible visual adverse events and abnormalities of liver function tests are observed in $20 \%$ to $40 \%$ and $5 \%$ to $15 \%$ of patients treated with voriconazole, respectively. Efficacy of and/or tolerance to voriconazole may be affected by great variability in blood levels caused by nonlinear pharmacokinetics, polymorphism of cytochrome CYP2C19, drug-drug interactions and hepatic dysfunction [75-77]. Monitoring of circulating drug concentrations to target trough blood values between 1-2 and $6 \mathrm{mg} / \mathrm{l}$ would appear prudent, especially during the acute phase of lifethreatening infections $[78,79]$.

Itraconazole (an azole that may be admininstered by oral and intravenous routes) and posaconazole (a new oral azole with a broad spectrum of antifungal activity against Candida spp., Aspergillus spp. and other emerging molds, including Fusarium spp. and zygomycetes) have been shown to be efficacious for treatment of oropharyngeal candidiasis $[80,81]$. However, no comparative clinical trials in patients with candidaemia have been performed with these antifungal agents, and their efficacy in this clinical setting remains to be determined. One concern, however, might be the potential risk for development of cross-resistance, which could limit the utility of new azoles for therapy of infections due to nonalbicans Candida spp.

\section{Echinocandins}

Echinocandins are a new class of parenteral antifungal agents that inhibit the synthesis of $\beta-(1,3)$-D-glucan in the fungal cell wall [82]. These compounds are fungicidal in vitro against C. albicans and non-albicans Candida spp. No cross-resistance with azoles has yet been reported. Three agents are available for clinical use [42,83]: caspofungin, micafungin and anidulafungin. The safety profile of echinocandins is excellent, with few reported adverse events (abnormal liver function tests, phlebitis, or histamine-like reactions). Drug-drug interactions with some medications have been observed with caspofungin (for example, with rifampicin, anticonvulsants, tacrolimus, cyclosporin, protease inhibitors and non-nucleoside reverse transcriptase inhibitors).

Caspofungin was the first echinocandin to be licensed for the treatment of invasive mycoses, including candidiasis [82]. In immunocompromised (mainly HIV-positive) patients with oropharyngeal and/or oesophageal candidiasis, caspofungin was found to be as effective as amphotericin B deoxycholate or fluconazole [84-86]. In a multicentre trial conducted inpatients with invasive candidiasis, caspofungin $(50 \mathrm{mg} /$ day after a $70 \mathrm{mg}$ loading dose) was at least as efficacious as and less toxic than amphotericin B deoxycholate (0.6 to $1 \mathrm{mg} / \mathrm{kg}$ per day) [32]. Recent reports have described the emergence of resistance to caspofungin in patients with oesophagitis, candidaemia and endocarditis [3]. In a multicentre, randomized, double-blind trial, micafungin $(100 \mathrm{mg} /$ day) was as effective as and less toxic than liposomal amphotericin B (3 mg/kg per day) for first-line therapy of candidaemia or invasive candidiasis [34]. In a randomized, double-blind study conducted in patients with invasive candidiasis [35], anidulafungin (100 mg/day after a $200 \mathrm{mg}$ loading dose) was observed to be superior to fluconazole ( $400 \mathrm{mg} /$ day after a $800 \mathrm{mg}$ loading dose), but the study was reported to show noninferiority after removal of the centre that enrolled the largest number of patients. A recent, randomized, double-blind study comparing micafungin (100 or $150 \mathrm{mg} /$ day) and caspofungin (70 mg loading dose and then 50 mg/day) in 595 adult patients with candidaemia or invasive candidiasis [30] reported noninferior efficacy of micafungin compared with that of caspofungin and similar safety profiles for the two compounds.

Thus, recent studies have shown that echinocandins are efficacious and safe, explaining why this new class of antifungal agents has assumed a prominent role in the management of patients with invasive candidiasis.

\section{Combinations of antifungal agents}

Given the poor prognosis of Candida sepsis in critically ill patients, clinicians have shown interest in using combinations of antifungal agents of different classes. Amphotericin B deoxycholate and 5-flucytosine have been shown to be synergistic in vitro and in experimental models of candidiasis [87-89]. Combination of fluconazole and amphotericin B has been shown to be antagonistic in experimental models of aspergillosis, but not in models of invasive candidiasis $[90,91]$. However, there is a dearth of information available from few clinical studies. In a randomized, double-blind study conducted in non-neutropenic patients with candidaemia [92], high-dose fluconazole ( $800 \mathrm{mg} /$ day intravenously) was compared with a combination of fluconazole $(800 \mathrm{mg} /$ day intravenously) and amphotericin B deoxycholate $(0.7 \mathrm{mg} / \mathrm{kg}$ per day intravenously). At first glance, the efficacy of combination therapy was slightly superior to that of monotherapy (success: 69\% versus 56\%), especially in patients with an APACHE II score ranging between 10 and 22. However, there were statistically significant differences in baseline covariates between the two groups, such as APACHE II score, which was lower in the combination treatment arm. Until clinical trials are reported that demonstrate efficacy and safety, the indiscriminate use of combination therapy in patients with invasive candidiasis should be discouraged. 


\section{This article is part of a review series on Infection, edited by Steven Opal.}
Other articles in the series can be found online at http://ccforum.com/articles/ theme-series.asp?series $=\mathrm{CC} \_$Infection

\section{Conclusion}

Invasive candidiasis is the most frequent invasive mycosis in critically ill patients. Changing epidemiology with increased non-albicans Candida spp., nonspecific risk factors and clinical presentation, and late diagnosis with culture-based methods are major challenges in the management of invasive candidiasis. Preventive strategies targeting patients with a high-risk profile, development of new noninvasive diagnostic tools that allow early diagnosis and therapy, and extension of the therapeutic armamentarium with new agents are encouraging recent advances that may allow us to overcome Candida infections.

\section{Competing interests}

The authors declare that they have no competing interests.

\section{References}

1. Martin GS, Mannino DM, Eaton S, Moss M: The epidemiology of sepsis in the United States from 1979 through 2000. N Engl J Med 2003, 348:1546-1554.

2. Lagrou K, Verhaegen J, Peetermans WE, De RT, Maertens J, Van WE: Fungemia at a tertiary care hospital: incidence, therapy, and distribution and antifungal susceptibility of causative species. Eur J Clin Microbiol Infect Dis 2007, 26:541-547.

3. Pfaller MA, Diekema DJ: Epidemiology of invasive candidiasis: a persistent public health problem. Clin Microbiol Rev 2007, 20:133-163.

4. Marchetti O, Bille J, Fluckiger U, Eggimann P, Ruef C, Garbino J, Calandra T, Glauser MP, Tauber MG, Pittet D: Epidemiology of candidemia in Swiss tertiary care hospitals: secular trends, 1991-2000. Clin Infect Dis 2004, 38:311-320.

5. Patterson TF, Kirkpatrick WR, White M, Hiemenz JW, Wingard JR, Dupont B, Rinaldi MG, Stevens DA, Graybill JR: Invasive aspergillosis. Disease spectrum, treatment practices, and outcomes. I3 Aspergillus Study Group. Medicine (Baltimore) 2000, 79:250-260.

6. Lin SJ, Schranz J, Teutsch SM: Aspergillosis case-fatality rate: systematic review of the literature. Clin Infect Dis 2001, 32: 358-366.

7. Bille J, Marchetti $O$, Calandra T: Changing face of health-care associated fungal infections. Curr Opin Infect Dis 2005, 18: 314-319.

8. Richards MJ, Edwards JR, Culver DH, Gaynes RP: Nosocomial infections in combined medical-surgical intensive care units in the United States. Infect Control Hosp Epidemiol 2000, 21: 510-515.

9. Rangel-Frausto MS, Wiblin T, Blumberg HM, Saiman L, Patterson J, Rinaldi M, Pfaller M, Edwards JE Jr, Jarvis W, Dawson J, et al.: National epidemiology of mycoses survey (NEMIS): variations in rates of bloodstream infections due to Candida species in seven surgical intensive care units and six neonatal intensive care units. Clin Infect Dis 1999, 29:253-258.

10. Wisplinghoff $H$, Seifert $H$, Wenzel RP, Edmond MB: Current trends in the epidemiology of nosocomial bloodstream infections in patients with hematological malignancies and solid neoplasms in hospitals in the United States. Clin Infect Dis 2003, 36:1103-1110.
11. Jarvis WR: Epidemiology of nosocomial fungal infections, with emphasis on Candida species. Clin Infect Dis 1995, 20:15261530.

12. Spencer RC: Predominant pathogens found in the European Prevalence of Infection in Intensive Care Study. Eur J Clin Microbiol Infect Dis 1996, 15:281-285.

13. Nolla-Salas J, Sitges-Serra A, Leon-Gil C, Martinez-Gonzalez J, Leon-Regidor MA, Ibanez-Lucia P, Torres-Rodriguez JM: Candidemia in non-neutropenic critically ill patients: analysis of prognostic factors and assessment of systemic antifungal therapy. Study Group of Fungal Infection in the ICU. Intensive Care Med 1997, 23:23-30.

14. Fluit AC, Jones ME, Schmitz FJ, Acar J, Gupta R, Verhoef J: Antimicrobial susceptibility and frequency of occurrence of clinical blood isolates in Europe from the SENTRY antimicrobial surveillance program, 1997 and 1998. Clin Infect Dis 2000, 30:454-460.

15. Nguyen $\mathrm{MH}$, Peacock JE Jr, Morris AJ, Tanner DC, Nguyen ML, Snydman DR, Wagener MM, Rinaldi MG, Yu VL: The changing face of candidemia: emergence of non-Candida albicans species and antifungal resistance. Am J Med 1996, 100:617623.

16. Pfaller MA, Diekema DJ, Gibbs DL, Newell VA, Meis JF, Gould IM, Fu W, Colombo AL, Rodriguez-Noriega E: Results from the ARTEMIS DISK Global Antifungal Surveillance study, 1997 to 2005: an 8.5-year analysis of susceptibilities of Candida species and other yeast species to fluconazole and voriconazole determined by CLSI standardized disk diffusion testing. $J$ Clin Microbiol 2007, 45:1735-1745.

17. Bassetti M, Righi E, Costa A, Fasce R, Molinari MP, Rosso R, Pallavicini FB, Viscoli C: Epidemiological trends in nosocomial candidemia in intensive care. BMC Infect Dis 2006, 6:21.

18. Sobel JD: The emergence of non-albicans Candida species as causes of invasive candidiasis and candidemia. Curr Infect Dis Rep 2006, 8:427-433.

19. Pappas PG, Rex JH, Sobel JD, Filler SG, Dismukes WE, Walsh TJ, Edwards JE: Guidelines for treatment of candidiasis. Clin Infect Dis 2004, 38:161-189.

20. Eggimann P, Garbino J, Pittet D: Management of Candida species infections in critically ill patients. Lancet Infect Dis 2003, 3:772-785.

21. Vincent JL, Anaissie $\mathrm{E}$, Bruining $\mathrm{H}$, Demajo $\mathrm{W}$, el-Ebiary $\mathrm{M}$, Haber J, Hiramatsu Y, Nitenberg G, Nystrom PO, Pittet D, et al.: Epidemiology, diagnosis and treatment of systemic Candida infection in surgical patients under intensive care. Intensive Care Med 1998, 24:206-216.

22. Buchner $\mathrm{T}$, Fegeler $\mathrm{W}$, Bernhardt $\mathrm{H}$, Brockmeyer $\mathrm{N}$, Duswald $\mathrm{KH}$ Herrmann M, Heuser D, Jehn U, Just-Nubling G, Karthaus M, et al.: Treatment of severe Candida infections in high-risk patients in Germany: consensus formed by a panel of interdisciplinary investigators. Eur J Clin Microbiol Infect Dis 2002, 21:337-352.

23. Dimopoulos G, Karabinis A, Samonis G, Falagas ME: Candidemia in immunocompromised and immunocompetent critically ill patients: a prospective comparative study. Eur J Clin Microbiol Infect Dis 2007, 26:377-384.

24. Rex JH, Walsh TJ, Sobel JD, Filler SG, Pappas PG, Dismukes WE, Edwards JE: Practice guidelines for the treatment of candidiasis. Infectious Diseases Society of America. Clin Infect Dis 2000, 30:662-678.

25. Wey SB, Mori M, Pfaller MA, Woolson RF, Wenzel RP: Risk factors for hospital-acquired candidemia. A matched casecontrol study. Arch Intern Med 1989, 149:2349-2353.

26. Voss A, le Noble JL, Verduyn Lunel FM, Foudraine NA, Meis JF: Candidemia in intensive care unit patients: risk factors for mortality. Infection 1997, 25:8-11.

27. Blot SI, Vandewoude $\mathrm{KH}$, Hoste EA, Colardyn FA: Effects of nosocomial candidemia on outcomes of critically ill patients. Am J Med 2002, 113:480-485.

28. Gudlaugsson O, Gillespie S, Lee K, Vande BJ, Hu J, Messer S, Herwaldt L, Pfaller M, Diekema D: Attributable mortality of nosocomial candidemia, revisited. Clin Infect Dis 2003, 37: 1172-1177.

29. Wisplinghoff $H$, Bischoff $T$, Tallent SM, Seifert $H$, Wenzel RP, Edmond MB: Nosocomial bloodstream infections in US hospitals: analysis of 24,179 cases from a prospective nationwide surveillance study. Clin Infect Dis 2004, 39:309-317. 
30. Pappas PG, Rotstein CM, Betts RF, Nucci M, Talwar D, De Waele JJ, Vazquez JA, Dupont BF, Horn DL, Ostrosky-Zeichner L, et al.: Micafungin versus caspofungin for treatment of candidemia and other forms of invasive candidiasis. Clin Infect Dis 2007, 45:883-893.

31. Rex JH, Bennett JE, Sugar AM, Pappas PG, van der Horst CM, Edwards JE, Washburn RG, Scheld WM, Karchmer AW, Dine AP, et al:: A randomized trial comparing fluconazole with amphotericin B for the treatment of candidemia in patients without neutropenia. Candidemia Study Group and the National Institute. N Engl J Med 1994, 331:1325-1330.

32. Mora-Duarte J, Betts R, Rotstein C, Colombo AL, ThompsonMoya L, Smietana J, Lupinacci R, Sable C, Kartsonis N, Perfect J: Comparison of caspofungin and amphotericin B for invasive candidiasis. N Engl J Med 2002, 347:2020-2029.

33. Kullberg BJ, Sobel JD, Ruhnke M, Pappas PG, Viscoli C, Rex JH, Cleary JD, Rubinstein E, Church LW, Brown JM, et al.: Voriconazole versus a regimen of amphotericin B followed by fluconazole for candidaemia in non-neutropenic patients: a randomised non-inferiority trial. Lancet 2005, 366:1435-1442.

34. Kuse ER, Chetchotisakd P, da Cunha CA, Ruhnke M, Barrios C, Raghunadharao D, Sekhon JS, Freire A, Ramasubramanian V, Demeyer I, et al.: Micafungin versus liposomal amphotericin B for candidaemia and invasive candidosis: a phase III randomised double-blind trial. Lancet 2007, 369:1519-1527.

35. Reboli AC, Rotstein C, Pappas PG, Chapman SW, Kett DH, Kumar D, Betts R, Wible M, Goldstein BP, Schranz J, et al:: Anidulafungin versus fluconazole for invasive candidiasis. $N$ Engl J Med 2007, 356:2472-2482.

36. Wey SB, Mori M, Pfaller MA, Woolson RF, Wenzel RP: Hospitalacquired candidemia. The attributable mortality and excess length of stay. Arch Intern Med 1988, 148:2642-2645.

37. Wenzel RP: Nosocomial candidemia: risk factors and attributable mortality. Clin Infect Dis 1995, 20:1531-1534.

38. Rentz AM, Halpern MT, Bowden R: The impact of candidemia on length of hospital stay, outcome, and overall cost of illness. Clin Infect Dis 1998, 27:781-788.

39. Pittet D, Monod M, Suter PM, Frenk E, Auckenthaler R: Candida colonization and subsequent infections in critically ill surgical patients. Ann Surg 1994, 220:751-758.

40. Blumberg HM, Jarvis WR, Soucie JM, Edwards JE, Patterson JE, Pfaller MA, Rangel-Frausto MS, Rinaldi MG, Saiman L, Wiblin RT, et al.: Risk factors for candidal bloodstream infections in surgical intensive care unit patients: the NEMIS prospective multicenter study. The National Epidemiology of Mycosis Survey. Clin Infect Dis 2001, 33:177-186.

41. Pittet D, Wenzel RP: Nosocomial bloodstream infections. Secular trends in rates, mortality, and contribution to total hospital deaths. Arch Intern Med 1995, 155:1177-1184.

42. Chandrasekar PH, Sobel JD: Micafungin: a new echinocandin. Clin Infect Dis 2006, 42:1171-1178.

43. Pelz RK, Hendrix CW, Swoboda SM, ener-West M, Merz WG, Hammond J, Lipsett PA: Double-blind placebo-controlled trial of fluconazole to prevent candidal infections in critically ill surgical patients. Ann Surg 2001, 233:542-548.

44. Dupont $H$, Bourichon A, Paugam-Burtz C, Mantz J, Desmonts JM: Can yeast isolation in peritoneal fluid be predicted in intensive care unit patients with peritonitis? Crit Care Med 2003, 31:752-757

45. Ostrosky-Zeichner L: New approaches to the risk of Candida in the intensive care unit. Curr Opin Infect Dis 2003, 16:533-537.

46. Paphitou NI, Ostrosky-Zeichner L, Rex JH: Rules for identifying patients at increased risk for candidal infections in the surgical intensive care unit: approach to developing practical criteria for systematic use in antifungal prophylaxis trials. Med Mycol 2005, 43:235-243.

47. Ostrosky-Zeichner L, Sable C, Sobel J, Alexander BD, Donowitz G, Kan V, Kauffman CA, Kett D, Larsen RA, Morrison V, et al.: Multicenter retrospective development and validation of a clinical prediction rule for nosocomial invasive candidiasis in the intensive care setting. Eur J Clin Microbiol Infect Dis 2007, 26:271-276.

48. Leon C, Ruiz-Santana S, Saavedra P, Almirante B, Nolla-Salas J, varez-Lerma F, Garnacho-Montero J, Leon MA: A bedside scoring system ('Candida score') for early antifungal treatment in nonneutropenic critically ill patients with Candida colonization. Crit Care Med 2006, 34:730-737.
49. Garey KW, Rege M, Pai MP, Mingo DE, Suda KJ, Turpin RS Bearden DT: Time to initiation of fluconazole therapy impacts mortality in patients with candidemia: a multi-institutional study. Clin Infect Dis 2006, 43:25-31.

50. Reiss E, Morrison CJ: Nonculture methods for diagnosis of disseminated candidiasis. Clin Microbiol Rev 1993, 6:311-323.

51. Morris AJ, Byrne TC, Madden JF, Reller LB: Duration of incubation of fungal cultures. J Clin Microbiol 1996, 34:1583-1585.

52. Ascioglu S, Rex JH, de PB, Bennett JE, Bille J, Crokaert F, Denning DW, Donnelly JP, Edwards JE, Erjavec Z, et al.: Defining opportunistic invasive fungal infections in immunocompromised patients with cancer and hematopoietic stem cell transplants: an international consensus. Clin Infect Dis 2002, 34:7-14.

53. Yera H, Sendid B, Francois N, Camus D, Poulain D: Contribution of serological tests and blood culture to the early diagnosis of systemic candidiasis. Eur J Clin Microbiol Infect Dis 2001, 20: 864-870.

54. Sendid B, Poirot JL, Tabouret M, Bonnin A, Caillot D, Camus D, Poulain D: Combined detection of mannanaemia and antimannan antibodies as a strategy for the diagnosis of systemic infection caused by pathogenic Candida species. J Med Microbiol 2002, 51:433-442.

55. Sendid B, Tabouret M, Poirot JL, Mathieu D, Fruit J, Poulain D: New enzyme immunoassays for sensitive detection of circulating Candida albicans mannan and antimannan antibodies: useful combined test for diagnosis of systemic candidiasis. $J$ Clin Microbiol 1999, 37:1510-1517.

56. Mori T, Ikemoto H, Matsumura M, Yoshida M, Inada K, Endo S, Ito A, Watanabe S, Yamaguchi $H$, Mitsuya $M$, et al.: Evaluation of plasma $(1->3)$-beta-D-glucan measurement by the kinetic turbidimetric Limulus test, for the clinical diagnosis of mycotic infections. Eur J Clin Chem Clin Biochem 1997, 35:553-560.

57. Obayashi T, Yoshida M, Mori T, Goto H, Yasuoka A, Iwasaki $H$, Teshima H, Kohno S, Horiuchi A, Ito A, et al:: Plasma $(1->3)$ beta-D-glucan measurement in diagnosis of invasive deep mycosis and fungal febrile episodes. Lancet 1995, 345:17-20.

58. Odabasi Z, Mattiuzzi G, Estey E, Kantarjian H, Saeki F, Ridge RJ, Ketchum PA, Finkelman MA, Rex JH, Ostrosky-Zeichner L: BetaD-glucan as a diagnostic adjunct for invasive fungal infections: validation, cutoff development, and performance in patients with acute myelogenous leukemia and myelodysplastic syndrome. Clin Infect Dis 2004, 39:199-205.

59. Ostrosky-Zeichner L, Alexander BD, Kett DH, Vazquez J, Pappas PG, Saeki F, Ketchum PA, Wingard J, Schiff R, Tamura H, et al.: Multicenter clinical evaluation of the $(1->3)$ beta-D-glucan assay as an aid to diagnosis of fungal infections in humans. Clin Infect Dis 2005, 41:654-659.

60. Morace G, Pagano L, Sanguinetti M, Posteraro B, Mele L, Equitani F, D'Amore G, Leone G, Fadda G: PCR-restriction enzyme analysis for detection of Candida DNA in blood from febrile patients with hematological malignancies. J Clin Microbiol 1999, 37:1871-1875.

61. Einsele H, Hebart H, Roller G, Loffler J, Rothenhofer I, Muller CA, Bowden RA, van BJ, Engelhard D, Kanz L, et al.: Detection and identification of fungal pathogens in blood by using molecular probes. J Clin Microbiol 1997, 35:1353-1360.

62. Garbino J, Lew DP, Romand JA, Hugonnet S, Auckenthaler R, Pittet D: Prevention of severe Candida infections in nonneutropenic, high-risk, critically ill patients: a randomized, doubleblind, placebo-controlled trial in patients treated by selective digestive decontamination. Intensive Care Med 2002, 28:17081717.

63. Slotman GJ, Burchard KW: Ketoconazole prevents Candida sepsis in critically ill surgical patients. Arch Surg 1987, 122: 147-151.

64. Savino JA, Agarwal N, Wry P, Policastro A, Cerabona T, Austria L: Routine prophylactic antifungal agents (clotrimazole, ketoconazole, and nystatin) in nontransplant/nonburned critically ill surgical and trauma patients. J Trauma 1994, 36:20-25.

65. Eggimann P, Francioli P, Bille J, Schneider R, Wu MM, Chapuis G, Chiolero R, Pannatier A, Schilling J, Geroulanos S, et al:: Fluconazole prophylaxis prevents intra-abdominal candidiasis in high-risk surgical patients. Crit Care Med 1999, 27:10661072.

66. Lumbreras C, Cuervas-Mons V, Jara P, del PA, Turrion VS, Barrios C, Moreno E, Noriega AR, Paya CV: Randomized trial of flu- 
conazole versus nystatin for the prophylaxis of Candida infection following liver transplantation. $J$ Infect Dis 1996, 174:583588.

67. Rex JH, Sobel JD: Prophylactic antifungal therapy in the intensive care unit. Clin Infect Dis 2001, 32:1191-1200.

68. Calandra T, Marchetti O: Clinical trials of antifungal prophylaxis among patients undergoing surgery. Clin Infect Dis 2004, Suppl 4:185-192.

69. Playford EG, Webster AC, Sorrell TC, Craig JC: Antifungal agents for preventing fungal infections in non-neutropenic critically ill patients. Cochrane Database Syst Rev 2006, 1: CD004920.

70. Piarroux R, Grenouillet F, Balvay P, Tran V, Blasco G, Millon L, Boillot A: Assessment of preemptive treatment to prevent severe candidiasis in critically ill surgical patients. Crit Care Med 2004, 32:2443-2449.

71. Tsuruta R, Mizuno H, Kaneko T, Oda Y, Kaneda K, Fujita M, Inoue $\mathrm{T}$, Kasaoka S, Maekawa T: Preemptive therapy in nonneutropenic patients with Candida infection using the Japanese guidelines. Ann Pharmacother 2007, 41:1137-1143.

72. Bowden RA, Cays M, Gooley T, Mamelok RD, van Burik JA: Phase I study of amphotericin B colloidal dispersion for the treatment of invasive fungal infections after marrow transplant. J Infect Dis 1996, 173:1208-1215.

73. Noskin GA, Pietrelli L, Coffey G, Gurwith M, Liang U: Amphotericin B colloidal dispersion for treatment of candidemia in immunocompromised patients. Clin Infect Dis 1998, 26:461467.

74. Johnson LB, Kauffman CA: Voriconazole: a new triazole antifungal agent. Clin Infect Dis 2003, 36:630-637.

75. Boyd AE, Modi S, Howard SJ, Moore CB, Keevil BG, Denning DW: Adverse reactions to voriconazole. Clin Infect Dis 2004, 39:1241-1244

76. Smith J, Safdar N, Knasinski V, Simmons W, Bhavnani SM, Ambrose PG, Andes D: Voriconazole therapeutic drug monitoring. Antimicrob Agents Chemother 2006, 50:1570-1572.

77. Pascual A, Nieth V, Calandra T, Bille J, Bolay S, Decosterd LA, Buclin T, Majcherczyk PA, Sanglard D, Marchetti O: Variability of voriconazole plasma levels measured by new high-performance liquid chromatography and bioassay methods. Antimicrob Agents Chemother 2007, 51:137-143.

78. Dodds Ashley ES, Lewis R, Lewis JL, Martin C, Andes D. Pharmcology of systemic antifungal agents. Clin Infect Dis 2006, Suppl 43:28-39.

79. Pascual A, Calandra T, Bolay S, Buclin T, Bille J, Marchetti O: Voriconazole therapeutic drug monitoring in patients with invasive mycoses improves efficacy and safety outcomes. Clin Infect Dis 2008, 46:201-211.

80. Vazquez JA, Skiest DJ, Nieto L, Northland R, Sanne I, Gogate J, Greaves W, Isaacs R: A multicenter randomized trial evaluating posaconazole versus fluconazole for the treatment of oropharyngeal candidiasis in subjects with HIV/AIDS. Clin Infect Dis 2006, 42:1179-1186.

81. Wilcox CM, Darouiche RO, Laine L, Moskovitz BL, Mallegol I, Wu $\mathrm{J}$ : A randomized, double-blind comparison of itraconazole oral solution and fluconazole tablets in the treatment of esophageal candidiasis. J Infect Dis 1997, 176:227-232.

82. Denning DW: Echinocandin antifungal drugs. Lancet 2003, 362:1142-1151.

83. Vazquez JA, Sobel JD: Anidulafungin: a novel echinocandin. Clin Infect Dis 2006, 43:215-222.

84. Villanueva A, Arathoon EG, Gotuzzo E, Berman RS, DiNubile MJ, Sable CA: A randomized double-blind study of caspofungin versus amphotericin for the treatment of candidal esophagitis. Clin Infect Dis 2001, 33:1529-1535.

85. Villanueva A, Gotuzzo E, Arathoon EG, Noriega LM, Kartsonis NA, Lupinacci RJ, Smietana JM, DiNubile MJ, Sable CA: A randomized double-blind study of caspofungin versus fluconazole for the treatment of esophageal candidiasis. Am J Med 2002, 113:294-299.

86. Arathoon EG, Gotuzzo E, Noriega LM, Berman RS, DiNubile MJ, Sable CA: Randomized, double-blind, multicenter study of caspofungin versus amphotericin B for treatment of oropharyngeal and esophageal candidiases. Antimicrob Agents Chemother 2002, 46:451-457.

87. Polak A: Combination therapy with antifungal drugs. Mycoses 1988, Suppl 2:45-53
88. Thaler M, Bacher J, O'Leary T, Pizzo PA: Evaluation of singledrug and combination antifungal therapy in an experimental model of candidiasis in rabbits with prolonged neutropenia. $J$ Infect Dis 1988, 158:80-88.

89. Kontoyiannis DP, Lewis RE: Combination chemotherapy for invasive fungal infections: what laboratory and clinical studies tell us so far. Drug Resist Updat 2003, 6:257-269.

90. Schaffner A, Frick PG: The effect of ketoconazole on amphotericin B in a model of disseminated aspergillosis. J Infect Dis 1985, 151:902-910.

91. Sanati H, Ramos CF, Bayer AS, Ghannoum MA: Combination therapy with amphotericin B and fluconazole against invasive candidiasis in neutropenic-mouse and infective-endocarditis rabbit models. Antimicrob Agents Chemother 1997, 41:13451348.

92. Rex JH, Pappas PG, Karchmer AW, Sobel J, Edwards JE, Hadley S, Brass C, Vazquez JA, Chapman SW, Horowitz HW, et al.: A randomized and blinded multicenter trial of high-dose fluconazole plus placebo versus fluconazole plus amphotericin $B$ as therapy for candidemia and its consequences in nonneutropenic subjects. Clin Infect Dis 2003, 36:1221-1228. 